\title{
Immunodominant Minor Histocompatibility Antigens Expressed by Mouse Leukemic Cells Can Serve as Effective Targets for T Cell Immunotherapy
}

\author{
Stéphane Pion, Pierre Fontaine, Chantal Baron, Martin Gyger, and Claude Perreault
}

Research Center, Maisonneuve-Rosemont Hospital, Montréal, Québec, Canada, HIT 2M4

\begin{abstract}
Numerous minor histocompatibility antigens (MiHAs) show tissue-specific expression and can induce vigorous $\mathbf{T}$ cell responses. They therefore represent attractive targets for leukemia immunotherapy mediated by adoptive transfer of $T$ cells. The main objective of this work was to determine whether MiHAs expressed by normal hematopoietic cells were present on leukemic cells and whether they could trigger lysis by cytotoxic T lymphocytes (CTLs). CTL assays showed that mouse leukemic cells of both lymphoid and myeloid lineages were sensitive to CTLs targeted toward some but not all MiHAs. In four out of four strain combinations in which we primed CTLs against immunodominant MiHAs, effectors killed leukemic blasts, whereas no cytotoxicity was observed when CTLs were targeted toward four immunorecessive MiHAs. Testing of HPLC fractions obtained from normal and leukemic cells provided molecular evidence that leukemic blasts expressed only some of the MiHAs found on normal mouse hematopoietic cells. Decreased density of $\mathrm{H}-2$ class I molecules at the surface of leukemic cells suggests that down-regulation of genes encoding either class I molecules or proteins involved in antigen processing played a role in the aberrant expression of MiHAs. In vivo resistance to the leukemic cells by various strains of mice correlated with in vitro CTL activity. These results show that leukemic cells express only some (immunodominant) MiHAs and suggest that this subset of MiHAs represent prime targets for adoptive immunotherapy. ( $J$. Clin. Invest. 1995. 95:1561-1568.) Key words: cancer $\cdot$ lymphocyte $\cdot$ peptide $\cdot$ major histocompatibility complex $\bullet$ immunosurveillance
\end{abstract}

\section{Introduction}

Both class I and class II MHC molecules bind and present self peptides that are derived from the proteolysis of endogenous

Address correspondence to Claude Perreault, M.D., Research Center, Maisonneuve-Rosemont Hospital, 5415 de l'Assomption Blvd., Montreal, Québec, Canada H1T 2M4. Phone: 514-252-3557; FAX: 514-2523569; Internet: perreauc@ere.umontreal.ca.

Received for publication 29 September 1994 and in revised form 7 December 1994.

1. Abbreviations used in this paper: CTL, cytotoxic T lymphocyte; GVHD, graft-versus-host disease; GVL, graft-versus-leukemia; MESF, molecules of equivalent soluble fluorochrome; MiHA, minor histocompatibility antigen; TFA, trifluoroacetic acid.

J. Clin. Invest.

(C) The American Society for Clinical Investigation, Inc.

$0021-9738 / 95 / 04 / 1561 / 08 \quad \$ 2.00$

Volume 95, April 1995, 1561-1568 proteins $(1,2)$. Some of these self peptides, known as minor histocompatibility antigens (MiHAs), ${ }^{1}$ are polymorphic and can trigger $\mathrm{T}$ cell responses between $\mathrm{MHC}$-identical individuals (3-5). Expression of MiHAs as well as other nonpolymorphic MHC-associated self peptides contributes in shaping the $\mathrm{T}$ cell repertoire, since they influence both positive and negative selection (6-8). Additionally, as $\mathrm{T}$ cells can detect a single amino acid substitution in MHC ligands, expression of self peptides allows $\mathrm{T}$ cells to check the integrity of the mammalian genome ( gene $\rightarrow$ endogenous protein $\rightarrow$ MHC-associated self peptide $\rightarrow$ target for immunosurveillance) $(9,10)$. Thus, T lymphocytes can reject cells that display abnormal self peptides after mutation, translocation, or viral infection $(11,12)$.

MiHAs may represent ideal targets for cancer immunotherapy, since the expression of many of them is tissue specific and can trigger vigorous $T$ cell responses $(3,13,14)$. This assertion is supported by the observation of the graft-versus-leukemia (GVL) effect after allogeneic bone marrow transplantation between MHC-identical/MiHA-different individuals (15, 16). The remarkable strength of the anti-MiHA GVL effect provides the most convincing clinical evidence for the effectiveness of tumor immunity in man $(17,18)$. The GVL reaction is initiated by donor $\mathrm{T}$ cells and can be triggered by as yet unidentified MiHAs that are expressed on normal hematopoietic cells (1922). Unfortunately, the GVL effect is linked with graft-versushost disease (GVHD). However, since several MiHAs are tissue or cell lineage specific, it may be possible to dissociate GVHD and GVL effect at the clonal level $(3,11)$. According to this hypothesis, the adoptive transfer of $T$ cell clones that are directed against MiHAs expressed only by the host's hematopoietic cells, and absent on nonhematopoietic cells, could allow us to obtain a powerful GVL effect without GVHD. Such manipulation of $\mathrm{T}$ cell responses aimed at the eradication of leukemic cells requires fundamental knowledge regarding MiHA expression by these cells.

The goal of this work was to evaluate MiHA expression by lymphoid and myeloid leukemic cells. Specifically, we wanted to determine whether MiHAs expressed by normal hematopoietic cells were present on leukemic cells and whether they could trigger lysis by cytotoxic T lymphocytes (CTLs). In addition, the relation between sensitivity to CTLs in vitro and in vivo resistance to leukemic cells was examined.

\section{Methods}

Mice. The following strains of mice were purchased from the Jackson Laboratory (Bar Harbor, ME): ABY/SnJ, C3H.SW/SnJ, C57BL/6J, B6.C-H-1 ${ }^{b} /$ By, B6.C-H-7 $/$ By, B6.C-H-25 $/$ By, B6.C-H- ${ }^{d} / a B y$, C57BL/10SnJ, B10.LP-H-3 ${ }^{\mathrm{b}} / \mathrm{Sn}, \mathrm{B} 10.129(21 \mathrm{~m}) / \mathrm{SnH}-4^{\mathrm{b}}, \mathrm{LP} / \mathrm{J}$, and $129 / \mathrm{J}$. All of these strains are $\mathrm{H}-2^{\mathrm{b}}$ except for B6.C-H-2 $/ \mathrm{aBy}$, which is $\mathrm{H}-2^{\mathrm{d}}$. We used only male mice aged between 6 and 16 wk. All animals were maintained on acidified drinking water and under normal 
housing conditions according to the standards of the Canadian Committee for Animal Protection.

Tumor cells. The tumor cell lines used in this investigation were purchased from the American Type Culture Collection (Rockville, MD). EL-4 and C1498 are leukemic cell lines of C57BL/6J origin. EL-4 cells are T lymphoblasts, and C1498 are myeloblasts (23). Both were maintained in DME supplemented with $100 \mathrm{U} / \mathrm{ml}$ penicillin $\mathrm{G}$, $100 \mu \mathrm{g} / \mathrm{ml}$ streptomycin, $2 \mathrm{mM}$ of L-glutamine, and either $10 \%$ horse serum (Hyclone, Logan, UT) for EL-4 or $10 \%$ FCS (Gibco Laboratories, Grand Island, NY) for C1498.

Generation of anti-MiHA CTLs. All mice except for B10.LP-H-3 ${ }^{\text {b }}$ $\mathrm{Sn}$ and $\mathrm{B} 10.129(21 \mathrm{~m}) / \mathrm{SnH}-4^{\mathrm{b}}$ were primed intraperitoneally with 2 $\times 10^{7}$ cells of a 1:1 mixture of C57BL/6J spleen and bone marrow cells. B10.LP-H-3 $/ \mathrm{Sn}$ and B10.129 $(21 \mathrm{~m}) / \mathrm{SnH}-4^{\mathrm{b}}$ mice were immunized with C57BL/10SnJ cells instead of C57BL/6J cells. Primed mice were killed $14 \mathrm{~d}$ after immunization, and their spleens were aseptically removed and crushed using a glass pylon to obtain a single-cell suspension. These effector cells $\left(5 \times 10^{6}\right.$ cells per $\left.\mathrm{ml}\right)$ were then restimulated for $5 \mathrm{~d}$ in culture medium (RPMI 1640, 10\% FCS, $4 \mathrm{mM}$ L-glutamine, $10 \mathrm{mM}$ Hepes buffer, $50 \mu \mathrm{M}$ 2-mercaptoethanol, $100 \mathrm{U} / \mathrm{ml}$ penicillin $\mathrm{G}, 100 \mu \mathrm{g} / \mathrm{ml}$ streptomycin) with an equal number of irradiated ( 25 Gy) stimulator spleen and bone marrow cells of the same mouse strain used for in vivo priming (C57BL/6J or C57BL/10SnJ).

CTL assays. Cytotoxic activity of the effector cells was assessed on day 5 of the mixed leukocyte culture (MLC) in a standard ${ }^{51} \mathrm{Cr}$ release assay and performed in microtiter plates with U-shaped wells. Target blast cells were prepared by culturing C57BL/6J spleen cells with 2 $\mu \mathrm{g} / \mathrm{ml}$ concanavalin A (Con A; Sigma Chemical Co., St. Louis, MO) for $48 \mathrm{~h}$. Tumor cells were in log-phase growth when used in the assay. Target cells were labeled with $100 \mu \mathrm{Ci}$ of $\mathrm{Na}_{2}{ }^{51} \mathrm{Cr}$ (Du Pont Co., Wilmington, DE) for $90 \mathrm{~min}$ and then washed three times with RPMI 1640 supplemented with 5\% FCS. Different ratios of effector cells were added to a fixed number of target cells $\left(5 \times 10^{3}\right.$ cells $)$ in a final volume of $200 \mu \mathrm{l}$ per well culture medium. The plates were centrifuged and then incubated for $3 \mathrm{~h}$ at $37^{\circ} \mathrm{C}$ in a humidified atmosphere of $5 \% \mathrm{CO}_{2}$. Plates were recentrifuged once more, and at the end of the incubation, $100 \mu \mathrm{l}$ of the supernatant was harvested from each well and counted in a gamma counter. All tests were done in triplicate. Spontaneous release was $<15 \%$. Results are expressed as a percentage of specific lysis calculated as follows: \% specific lysis $=100 \times($ experimental release - spontaneous release)/(maximum release - spontaneous release).

HPLC peptide fractionation. MiHAs were extracted from normal and leukemic cells by acid elution according to Storkus et al. (24). Briefly, $2 \times 10^{8}$ cells were suspended in $5 \mathrm{ml}$ of citrate-phosphate buffer $\left(0.131 \mathrm{M}\right.$ citric acid, $0.066 \mathrm{M} \mathrm{Na}_{2} \mathrm{HPO}_{4}, \mathrm{pH} \mathrm{3.3)}$ for $1 \mathrm{~min}$ at room temperature and were then centrifuged. The supernatants were collected and loaded onto a column (C18 Sep-Pak, Waters Associates, Milford, MA) previously washed with $100 \%$ acetonitrile and then distilled water $+0.1 \%$ trifluoroacetic acid (TFA). Peptides were eluted from the column with $80 \%$ acetonitrile in water, $0.1 \%$ TFA and collected. The acetonitrile was evaporated, and the peptide-containing sample was fractionated by HPLC on a Superpac PepS column (C18, 5 $\mu \mathrm{m}, 4 \times 250 \mathrm{~mm}$; Pharmacia Fine Chemicals, Piscataway, NJ). The solvents used were (A) $99.9 \%$ water, $0.1 \%$ TFA and (B) $99.9 \%$ acetonitrile, $0.1 \%$ TFA. Standard gradient consisted of the following linear step intervals: $100 \%$ A from 0 to $5 \mathrm{~min}, 0 \% \mathrm{~B}$ (in A) to $20 \% \mathrm{~B}$ (in A) from 5 to $10 \mathrm{~min}, 20 \% \mathrm{~B}$ (in $A$ ) to $55 \% \mathrm{~B}$ (in $\mathrm{A}$ ) from 10 to $55 \mathrm{~min}$, $55 \%$ B (in A) from 55 to $60 \mathrm{~min}, 55 \% \mathrm{~B}$ (in A) to $100 \% \mathrm{~B}$ (in A) from 60 to $70 \mathrm{~min}$, and $100 \% \mathrm{~B}$ (in A) to $0 \% \mathrm{~B}$ (in A) from 70 to 80 min. The flow rate was $1 \mathrm{ml} / \mathrm{min}$, and $1-\mathrm{ml}$ fractions were collected and lyophilized. In some experiments, a second high resolution HPLC fractionation was done. Fractions that were of interest in the standard HPLC fractionation were pooled and passed over the same Superpac PepS C18 column using the following gradient: $0 \%$ to $30 \%$ B (in A) from 0 to $120 \mathrm{~min}, 30 \%$ to $100 \% \mathrm{~B}$ (in A) from 120 to $130 \mathrm{~min}$ and $100 \%$ to $0 \%$ B (in A). Flow rate was $1 \mathrm{ml} / \mathrm{min}$. The reverse-phase HPLC system was equipped with a Waters 996 Photodiode Array, a Waters 6000A pump (solvent A), and a Waters M45 pump (solvent $B$ ).

CTL assay using peptide fractions. Lyophilized HPLC fractions were tested in a CTL assay using some modification to the CTL assay described earlier. Blast cells syngeneic to the effector cells were used as targets. These target cells were stimulated with $5 \mu \mathrm{g} / \mathrm{ml}$ Con A for 48 $\mathrm{h}$ at $37^{\circ} \mathrm{C}$ and then transferred to $26^{\circ} \mathrm{C}$ for $18 \mathrm{~h}$ in order to increase the number of "empty" class I molecules (25). Afterward, they were labeled at $37^{\circ} \mathrm{C}$ with $100 \mu \mathrm{Ci}$ of $\mathrm{Na}_{2}{ }^{51} \mathrm{Cr}$ for $90 \mathrm{~min}$ and washed three times with RPMI $+5 \%$ FCS. Each HPLC fraction was resuspended in $200 \mu \mathrm{l}$ of culture medium and sonicated for $15 \mathrm{~min}$. $50 \mu \mathrm{l}$ of each fraction was dispensed in triplicate into microtiter plates with $U$-shaped wells. In some experiments, dilutions were performed with the remaining $50 \mu \mathrm{l}$ of each fraction $(1: 5,1: 10,1: 50) .5 \times 10^{3}$ labeled target cells $(50 \mu \mathrm{l})$ were then mixed with the peptide fractions and incubated for $90 \mathrm{~min}$ at $37^{\circ} \mathrm{C}$. Afterward, effector cells were added at an effector/ target ratio of 100:1 for a final volume of $200 \mu \mathrm{l}$ per well and incubated for $4 \mathrm{~h}$ at $37^{\circ} \mathrm{C}$. Appropriate positive (allogeneic targets) and negative (syngeneic targets without peptide fractions) controls were performed.

Antibodies. The following monoclonal antibodies were used for phenotyping and quantification experiments: FITC-conjugated anti-H-2 $\mathrm{K}^{\mathrm{b}}$ (catalog \#06104D, PharMingen, San Diego, CA), FITC-conjugated anti-H-2 $\mathrm{D}^{\mathrm{b}}$ (catalog \#06114D, PharMingen), and FITC-conjugated anti-QA-2a (catalog \#06324D, PharMingen). Characterization of class I molecules was performed by incubating $10^{6}$ cells with the appropriate dilution of antibody for $30 \mathrm{~min}$ on ice. After three washes in PBS, the fluorescence was analyzed by flow cytometry on a flow cytometer (FACStrar ${ }^{\text {Plus }}$, Becton Dickinson Immunocytometry Systems, Mountain View, CA) equipped with a 2-W Argon ion laser operated at $200 \mathrm{~mW}$. The fluorochrome was excited with the 488-nm line, and the emission was collected through a DM530 \pm 15 filter.

Quantification of class I molecules. Relative quantification of class I molecules was evaluated using a FACStar ${ }^{\text {Plus }}$ flow cytometer. First, calibration of the cytometer was performed using Quantum 26p FITC calibrated beads (catalog \#826p, FCSC, Research Triangle Park, NC). This kit contained four populations of standards having different levels of fluorescence intensity expressed in molecules of equivalent soluble fluorochrome (MESF) ranging from 10,000 to $500,000 \mathrm{U}$ and a blank to measure the threshold fluorescence level of the instrument. Once the calibration was established, cells marked with one of three class I antibodies (anti-H-2 $\mathrm{K}^{\mathrm{b}}$, anti-H-2 $\mathrm{D}^{\mathrm{b}}$, or anti-QA-2a) were analyzed with the FACS, and values obtained were compared with a calibration plot to obtain an MESF value. MESF values were corrected for the different fluorescein to protein ratio of each antibody and for nonspecific fluorescence.

To obtain the diameter of the different cells studied, we used the FACStar ${ }^{\text {Plus }}$ pulse-width processing. We calibrated the width scale with 6-mm singlet and doublet unlabeled beads. Using the forward scatter channel parameter, we could evaluate the diameter of the cell population. We then calculated the relative density of each class I molecule on the cell's surface using the following formula: class I density = total MESF value $/ 4 \pi r^{2}$ where $r$ is the cell radius $\left(\mathrm{MESF} / \mu \mathrm{m}^{2}\right)$.

In vivo survival curves. Resistance of different strains of mice to EL-4 and C1498 tumor cells was evaluated. On day 0, naive or preimmunized mice were injected intravenously with $10^{7}$ EL-4 or C1498 tumor cells, and survival was observed up to day 100 postinjection. Preimmunized mice were primed intraperitoneally with $2 \times 10^{7}$ cells of a 1:1 mixture of C57BL/6J spleen and bone marrow cells $14 \mathrm{~d}$ before injection of the tumor cells.

\section{Results}

Lysis of leukemic cells by anti-MiHA CTLs. A variety of $\mathrm{H}-2^{\mathrm{b}}$ mice were primed in vivo and restimulated in vitro with C57BL/ $6 \mathrm{~J}$ (or C57BL/10SnJ in the case of C57BL/10SnJ congenic mice) spleen and marrow cells. These effectors differed from 

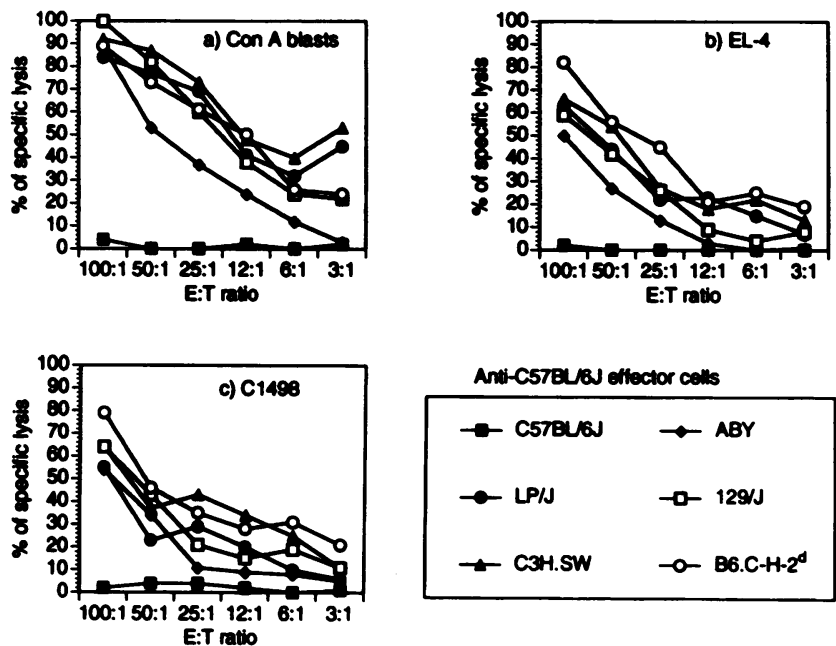

Figure 1. Lysis of normal and leukemic cells by CTLs differing from C57BL/6J at multiple MiHA loci. Such effectors recognized immunodominant MiHAs and were tested on three types of targets, $(a) \mathrm{C} 57 \mathrm{BL} /$ $6 \mathrm{~J}$ Con A blasts, $(b) \mathrm{EL}-4$, and $(c)$ C1498 tumor cells in a standard ${ }^{51} \mathrm{Cr}$ release assay. Results are of one out of three representative experiments.

immunizing cells by either one or multiple MiHA loci. Congenic B6-C-H-2 ${ }^{\text {d }}$ effectors were also tested as MHC-incompatible positive controls. Cytotoxicity was assessed on three types of target cells: C57BL/6J Con A blasts, EL-4, and C1498 leukemic cells. EL-4 and C1498 are lymphoblastic and myeloblastic cell lines of C57BL/6J origin, respectively. Target cell lysis depended on recognition of histocompatibility antigens and not of tumor-specific antigens, since effectors had been immunized only against normal spleen and marrow cells.

The four types of effectors differing from C57BL/6J at multiple MiHA loci (LP/J, 129/J, ABY/SnJ, and C3H.SW/ $\mathrm{SnJ}$ ) showed a strong cytotoxicity against both Con A blasts and leukemic cells (Fig. 1). However, in three out of three experiments, lysis of leukemic cells tended to be slightly lower than that of Con A blasts at lower effector/target ratios, particularly for C1498 myeloblasts (Fig. 1).

To get a more thorough evaluation of anti-MiHA CTL responses, we immunized effectors against the products of a single MiHA locus (H-1, H-7, H-9, H-25) or a single MiHA haplotype (H-3, H-4). Histocompatibility typing of mice used in these experiments is summarized in Table I. Lysis of EL-4 and C1498

Table I. MiHA Differences between C57BL/6J and C57BL/10SnJ Congenic Mice Tested in Fig. 2 (26-30)

\begin{tabular}{lll}
\hline \multicolumn{1}{c}{ Effector cells } & \multicolumn{1}{c}{$\begin{array}{c}\text { Immunizing } \\
\text { cells }\end{array}$} & \multicolumn{1}{c}{ MiHA targets } \\
\hline B6.C-H-1 & C57BL/6J & $\mathrm{H}-1^{\mathrm{c}}$ \\
B6.C-H-7 & C57BL/6J & $\mathrm{H}-7^{\mathrm{a}}$ \\
B6.C-H-25 & C57BL/6J & $\mathrm{H}-25^{\mathrm{b}}$ \\
C57BL $10 \mathrm{SnJ}$ & C57BL/6J & $\mathrm{H}-9$ (non a, non b) \\
B10.LP.H-3 & C57BL/10SnJ & $\mathrm{H}-3^{\mathrm{a}}$ haplotype \\
B10.129(21M).H-4 & C57BL/10SnJ & $\mathrm{H}-4^{\mathrm{a}}$ haplotype
\end{tabular}
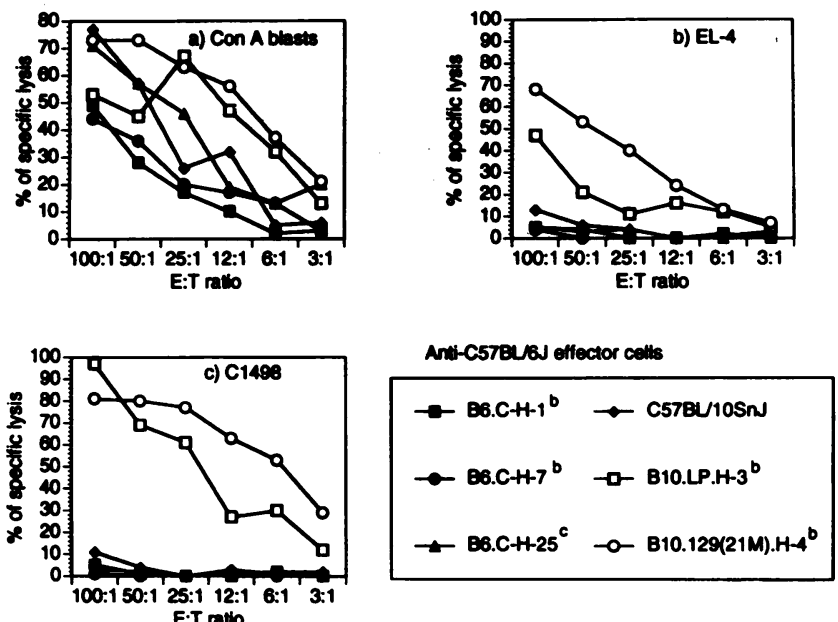

Figure 2. Lysis of normal and leukemic target cells by CTLs primed against a single MiHA or a single MiHA haplotype. Effectors differing from C57BL/6J at a single MiHA locus (B6.H- ${ }^{\mathrm{b}}, \mathrm{B} 6 . \mathrm{H}-7^{\mathrm{b}}, \mathrm{B} 6 . \mathrm{H}-25^{\mathrm{c}}$, and C57BL/10SnJ) or a single MiHA haplotype (B10.LP-H- $3^{b}$ and B10.129(21M)/SnH-4 $\left.{ }^{b}\right)$ were tested on three different target cells, $(a)$ C57BL/6J Con A blasts, $(b)$ EL-4, and (c) C1498 tumor cells in a standard ${ }^{51} \mathrm{Cr}$ release assay. Results are of one out of three representative experiments.

by anti-H-3 and anti-H-4 CTLs was similar to that of Con A blasts (Fig. 2). However, when CTLs were targeted to H-1, H7, H-9, and H-25 MiHAs, we observed a clear dichotomy between Con A blasts and leukemic cells, as the latter were completely resistant to lysis. Collectively, these results show that susceptibility of leukemic cells to lysis depends on the specificity of CTL effectors. CTLs generated by immunization with cells differing at multiple MiHA loci (Fig. 1) or at a few MiHA loci that form a "complex" (H-3 and H-4) kill both normal and leukemic cells $(29,30)$. However, the latter are resistant to CTLs directed against the product of a single MiHA locus.

In Vivo resistance to EL-4 and C1498 leukemic cells. Does the susceptibility of leukemic cells to lysis by diverse types of anti-MiHA CTLs correlate with the capacity of MiHA-incompatible host to reject leukemic cells? We injected intravenously $10^{7}$ leukemic cells into mouse strains used as a source of effector cells in Figs. 1 and 2. This represents a very large leukemic inoculum and thus an extremely stringent test of resistance to leukemic cells (Table II).

In naive recipients, LP/J and $129 / \mathrm{J}$ hosts showed a resistance to both $\mathrm{C} 1498$ and EL-4 cells. Indeed, following challenge with $\mathrm{C} 1498$ cells, LP/J showed the same survival rate $(80 \%)$ as B6.C-H-2 ${ }^{\mathrm{d}}$ hosts, which are MHC-different from the leukemic cells. Other types of naive recipients showed a $100 \%$ mortality rate.

We also tested whether preimmunization of recipients with normal C57BL/6J cells could influence resistance to EL-4 cells. The six varieties of mice that generated CTLs able to kill leukemic cells (as depicted in Figs. 1 and 2) showed practically total resistance to EL-4 cells. In contrast, immunization did not protect the three types of recipients whose anti-C57BL/6J MiHA CTLs were unable to lyse leukemic cells (B6.C-H-1 ${ }^{\text {b }}$, B6.C-H-7 ${ }^{\mathrm{b}}$, and B6.C-H-25 ${ }^{\mathrm{c}}$ ).

Thus, there was a striking correlation between in vitro CTL- 
Table II. Resistance of Naive and Preimmunized Mice to Leukemic Cells

\begin{tabular}{|c|c|c|c|c|c|c|c|c|c|}
\hline \multirow[b]{2}{*}{ Mice strain } & \multicolumn{3}{|c|}{ C1498 } & \multicolumn{3}{|c|}{ EL-4 } & \multicolumn{3}{|c|}{ EL-4 with preimmunization } \\
\hline & $\begin{array}{l}\text { Median } \\
\text { survival }\end{array}$ & $\begin{array}{c}\text { \% Survival } \\
\text { (day 100) }\end{array}$ & $n$ & $\begin{array}{l}\text { Median } \\
\text { survival }\end{array}$ & $\begin{array}{l}\text { \% Survival } \\
\text { (day 100) }\end{array}$ & $n$ & $\begin{array}{l}\text { Median } \\
\text { survival }\end{array}$ & $\begin{array}{c}\text { \% Survival } \\
\text { (day 100) }\end{array}$ & $\boldsymbol{n}$ \\
\hline & $d$ & & & $d$ & & & $d$ & & \\
\hline C57BL/6J & 18 & 0 & 10 & 24 & 0 & 10 & & ND & \\
\hline LP/J & $>100$ & 80 & 15 & 30 & 40 & 10 & $>100$ & 100 & 5 \\
\hline C3H.SW & 27 & 0 & 5 & & ND & & $>100$ & 100 & 5 \\
\hline $\mathrm{ABY}$ & 21 & 0 & 10 & 21 & 0 & 5 & $>100$ & 100 & 5 \\
\hline $129 / \mathrm{J}$ & 63 & 40 & 10 & 66 & 60 & 10 & $>100$ & 100 & 5 \\
\hline B6.C-H-2d & $>100$ & 80 & 10 & $>100$ & 90 & 10 & & ND & \\
\hline B6.C-H-1 ${ }^{b}$ & 13 & 0 & 10 & 23 & 0 & 5 & 22 & 0 & 5 \\
\hline B6.C-H-7 & 17 & 0 & 10 & 27 & 0 & 10 & 28 & 0 & 5 \\
\hline B6.C-H-25 & 12 & 0 & 10 & 22 & 0 & 10 & 23 & 0 & 5 \\
\hline B10.LP.H-3 & & ND & & & ND & & $>100$ & 100 & 5 \\
\hline B10.129(21M).H-4 & & ND & & & ND & & $>100$ & 80 & 5 \\
\hline
\end{tabular}

Mice were injected with $10^{7}$ EL-4 or C1498 tumor cells. Those that were preimmunized received $2 \times 10^{7}$ normal C57BL/6J cells intraperitoneally (or C57BL/10SnJ for B10.LP.H-3 ${ }^{b}$ and B10.129(21M).H-4 $4^{b}$ ) $14 \mathrm{~d}$ before tumor cell injection. C57BL/6J and B6.C-H-2 ${ }^{\mathrm{d}}$ were used, respectively, as syngeneic and MHC-different controls. $n=$ number of mice per group. ND, not determined.

mediated lysis and in vivo resistance. All mice that could generate CTLs capable of killing leukemic cells in vitro resisted the leukemic cells in vivo after they had been preimmunized. Some of them could do so even without preimmunization. Mice whose anti-MiHA CTLs did not lyse leukemic cells showed high susceptibility to leukemic challenge in vivo.

Expression of MHC class I molecules by leukemic cells. CTL responses vary directly with the surface density of MHC/ peptide complexes (31). H-1, H-7, H-25, and presumably $\mathrm{H}-$ 9 MiHAs are presented by MHC class I molecules $(28,32$, 33). As down-regulation of MHC class I molecules is frequently detected on neoplastic cells (34-36), we compared their cell surface density on normal and leukemic target cells (Table III). Compared with normal C57BL/6J Con A blasts, C1498 myeloblasts showed a much lower expression of class Ia $\left(H-2 K^{b}\right.$, and $\left.H-2 D^{b}\right)$ and class Ib (QA-2a) molecules. EL4 cells had a decreased expression of $\mathrm{H}-2 \mathrm{D}^{\mathrm{b}}$ and QA-2a molecules but near normal levels of $\mathbf{H}-2 \mathbf{K}^{\mathbf{b}}$.

Expression of MiHAs by leukemic cells. It would have been incorrect to assume that sensitivity to CTL-mediated lysis corre-

Table III. Surface Density of MHC Class I Molecules on Con A Blasts and Leukemic Cells

\begin{tabular}{lcccc}
\hline & & \multicolumn{3}{c}{ Class I density } \\
\cline { 3 - 5 } \multicolumn{1}{c}{ Cell type } & Radius & H-2K & H-2D & QA-2a \\
\hline & $\mu m$ & & $M E S F / \mu m^{2}$ \\
C57BL/6J blasts & 4.4 & $835 \pm 48$ & $1,085 \pm 196$ & $313 \pm 58$ \\
EL-4 & 7.3 & $671 \pm 28$ & $175 \pm 27$ & $113 \pm 15$ \\
C1498 & 4.7 & $392 \pm 67$ & $239 \pm 1$ & $1 \pm 0$ \\
& & & & \\
\hline
\end{tabular}

Fluorescence was measured as MESF units and MHC class I molecule density was calculated with the following formula: class I density $=$ MESF value $/ 4 \pi r^{2}$. lated with MiHA expression. For example, leukemic cells could have been resistant to lysis by some CTLs because they were deficient in accessory molecules, such as those involved in cell adhesion. To evaluate MiHA expression more directly, we extracted MHC-associated peptides from C57BL/6J Con A blasts as well as EL-4 and C1498 leukemic cells. HPLC fractions from these three sources were then used to sensitize target cells (Con A blasts syngeneic to effector cells) to CTL-mediated killing. This approach allowed semiquantitative comparison of MiHA expression by various cell types (37).

Peptides from C57BL/6J blasts showed a complex HPLC elution profile (Fig. $3 a$ ). When individual fractions were tested for the presence of $\mathrm{H}-25^{\mathrm{b}}$, fractions 22-24 were positive (Fig. $3 b$ ). These fractions were pooled and rechromatographed using a high resolution gradient (see Methods). After this second chromatography, positive fractions eluted with a single peak at 90-92 min (Fig. 4). In contrast, no activity was found in any HPLC fractions eluted from the same number $\left(10^{9}\right)$ of EL-4 or C1498 leukemic cells (data not shown). The absence of the target MiHA can explain why leukemic cells were resistant to anti-H-25 ${ }^{\mathrm{b}}$ CTLs.

In the $\mathrm{C} 3 \mathrm{H} . \mathrm{SW}$ anti-C57BL/6J combination, MiHA activity was found in two HPLC fractions containing peptides eluted from Con A blasts (Fig. $5 a$ ). Similar results were previously observed with the BALB.B anti-C57BL/6J combination (28). Fraction 18 was active up to at least a 1:10 dilution, whereas activity of fraction 23 was lost after a dilution of 1:5. When leukemic cells were used as a source of peptides, fraction 18 had "normal" activity, but no other fraction sensitized targets to lysis (Fig. 5, $b-c$ ). Thus, the major MiHA peptide recognized by C3H.SW anti-C57BL/6J CTL could be extracted from the two varieties of leukemic cells tested. Hence, sensitivity or resistance to anti-MiHA CTLs correlated with the presence or absence of target MiHA. It must be noted, however, that the activity of fraction 23 from leukemic cells was absent or at least severely decreased to $<20 \%$ of normal activity found on Con A blasts. 


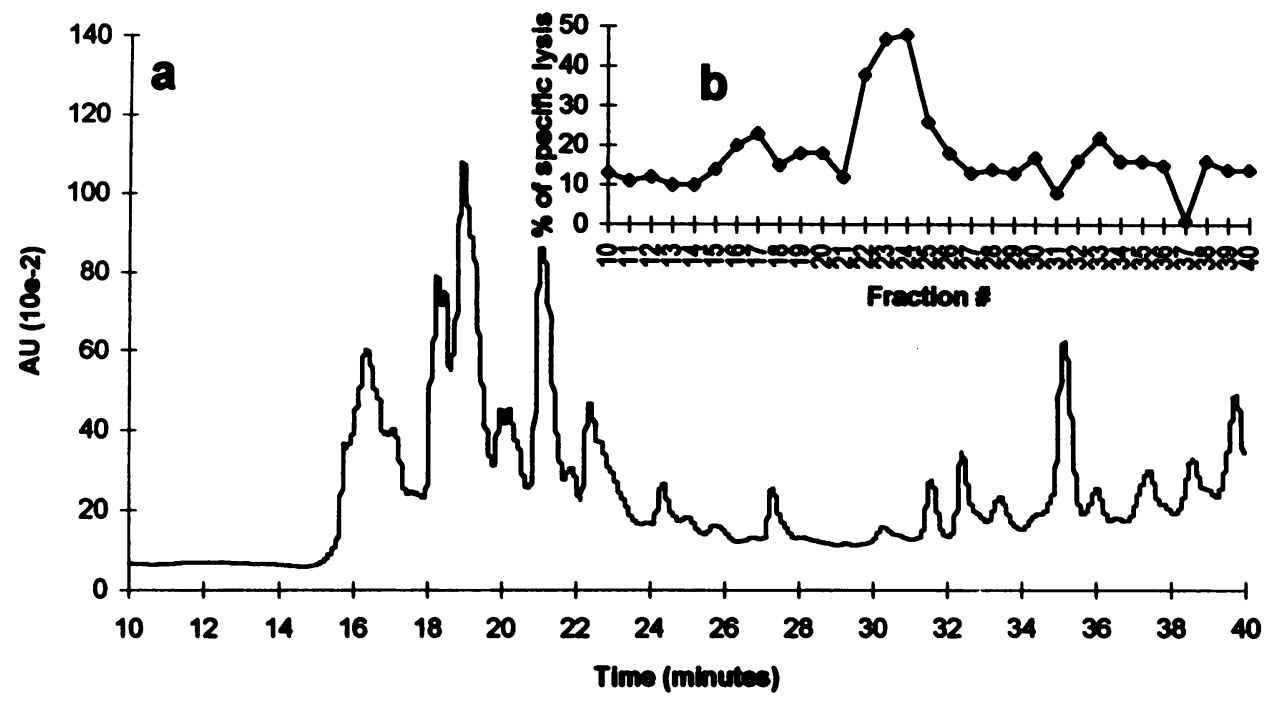

Figure 3. Expression of $\mathrm{H}-25^{\mathrm{b}} \mathrm{MiHA}$. (a) Standard resolution HPLC chromatogram of peptides eluted from $10^{9}$ C57BL/6J Con A blasts. (b) Individual fractions were incubated with B6.H-25 ${ }^{\mathrm{c}}$ Con A blasts and tested for recognition by $\mathrm{B} 6 . \mathrm{H}-25^{\mathrm{c}}$ effectors primed against C57BL/6J cells. Positive fractions were $22-24$. Each well contained the peptide extract equivalent of $25 \times 10^{7}$ cells, which is 10 times the lower limit of detection of the $\mathrm{H}-25^{\mathrm{b}}$ peptide (lower limit $=25$ $\times 10^{6}$ cell extract per well $)$.

\section{Discussion}

The experiments reported herein show that acute leukemic cells are susceptible to lysis by some but not all anti-MiHA CTLs. Furthermore, in vitro killing correlated with in vivo resistance to leukemic cells. The observation that lymphoblastic and myeloblastic mouse leukemic cells can be killed by CTLs obtained after immunization between mice differing by numerous MiHA genes is consistent with prior studies in man showing that myeloid leukemic cells can be killed by at least some anti-MiHA CTL clones $(38,39)$. The fact that only mice producing antiMiHA CTLs able to kill leukemic cells in vitro could reject (or at least control) these leukemic cells in vivo suggests that antiMiHA CTL assays have biological relevance. Although we cannot prove that the CTLs detected in vitro are responsible for in vivo resistance, this is certainly a strong possibility. Indeed, it has been shown that class I-restricted CTLs can be directly cytopathic for their target cells in vivo (40). A number of observations suggest that adoptive transfer of CTL clones targeted to hematopoietic MiHAs could generate a potent GVL effect without GVHD (reviewed in references 3,11). The present work shows that not all MiHAs would be adequate targets for such immunotherapy. Furthermore, the observation that the two unrelated leukemic cell lines used in our study exhibited the same pattern of sensitivity to anti-MiHA CTLs, comparable in vivo behavior following intravenous injection and similar MiHA expression, suggests that decreased expression of some MiHAs may be a common finding in leukemic cells of diverse origins.

Two indications suggest that the CTL activity detected in this work is targeted exclusively to MHC class I-associated peptides. First, mouse Con A blasts as well as EL-4 and C1498 leukemic cells do not express class II molecules. Furthermore, we have demonstrated in the LP anti-C57BL/6J strain combination that anti-MiHA CTL activity was mediated only by class I-restricted $\mathrm{CD}^{+}$T cell receptor $\alpha / \beta^{+}$CTL clones (41). To explain why leukemic cells were resistant to effectors immunized against a single MiHA (Fig. 2), we assessed the expression of the two components of the specific ligand recognized by these CTLs: MHC class I molecules and MiHA peptides.

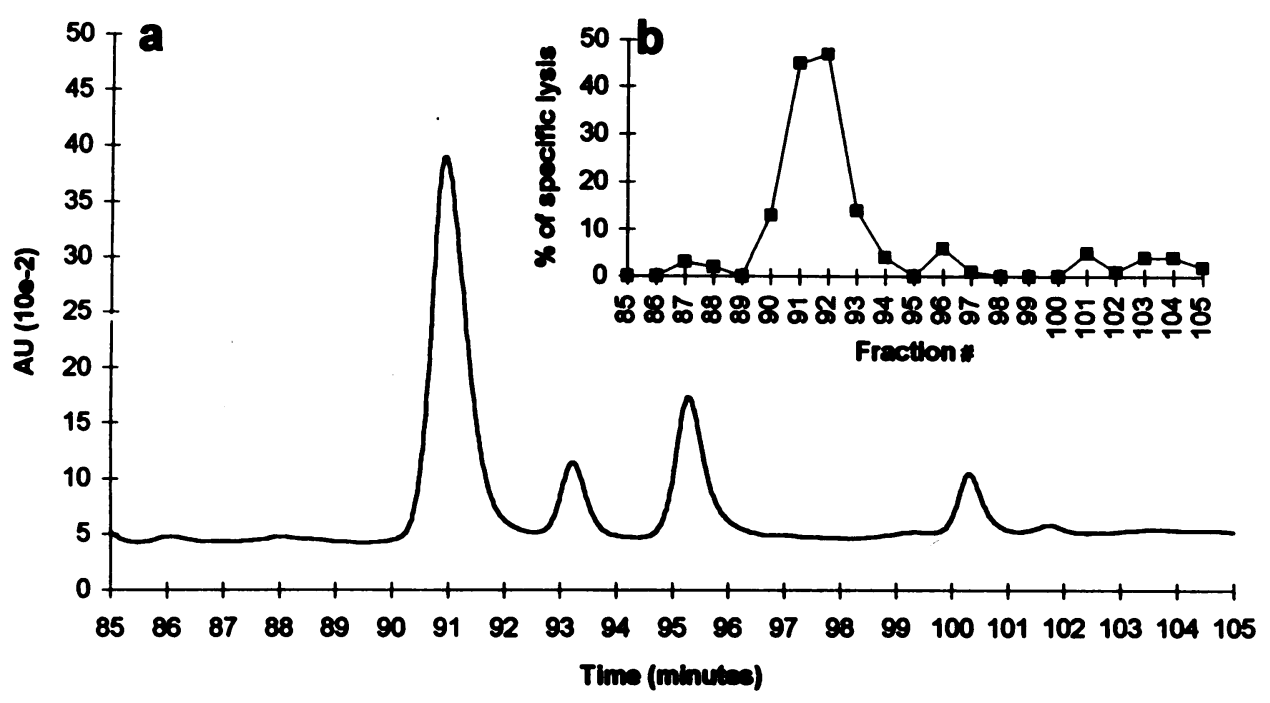

Figure 4. High resolution HPLC of fractions $22-24$. Active fractions were pooled and rechromatographed using a high resolution gradient. Same effectors and targets as for Fig. 3. 

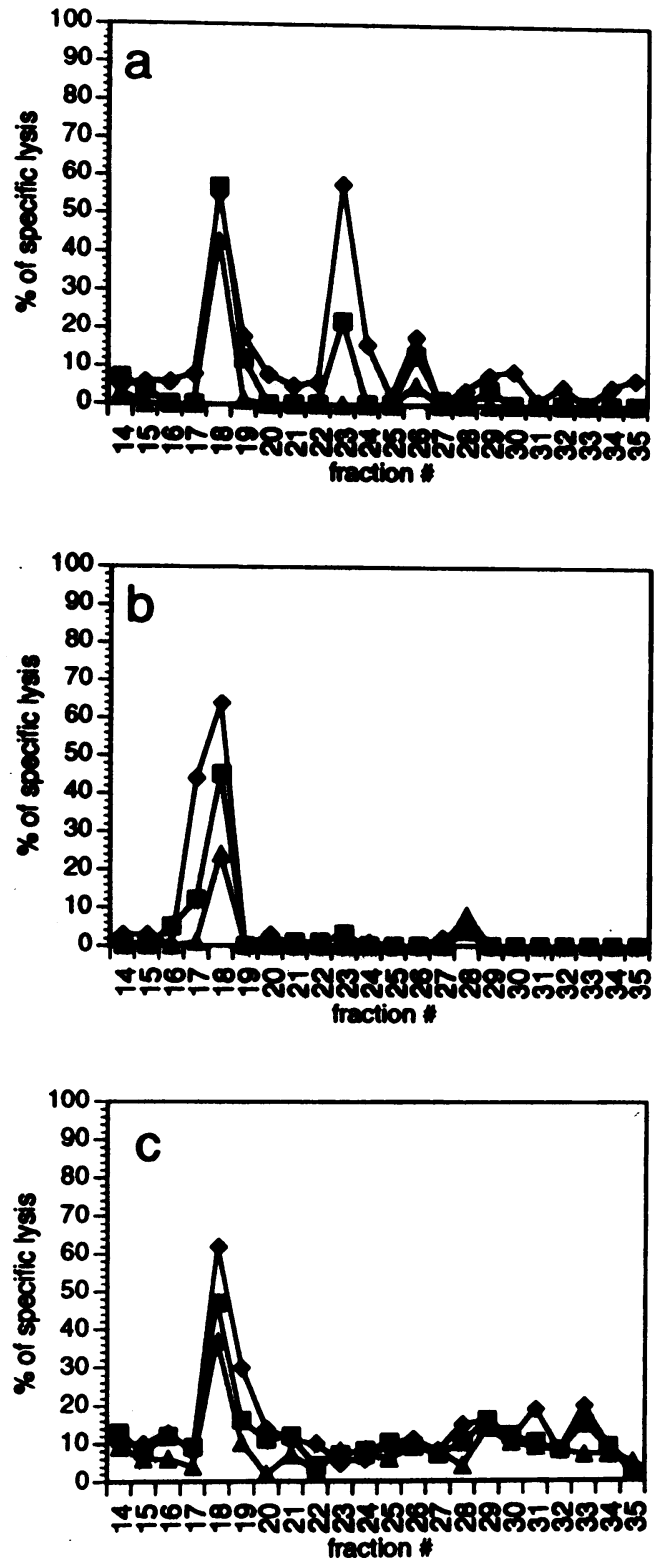

Figure 5. Expression of C57BL/6J MiHAs recognized by C3H.SW CTLs. Target cells were sensitized with peptides eluted from $(a)$ C57BL/6J Con A blasts, (b) EL-4 tumor cells, and (c) C1498 tumor cells. Effector cells were C3H.SW primed against C57BL/6J. Peptide dilution was neat $(\bullet), 1: 5(\square)$, and 1:10( $\triangle)$ (or the equivalent of 5 $\times 10^{7}, 10^{7}$, and $5 \times 10^{6}$ cell extract per well, respectively).

We found a decreased cell surface density of some or all class I molecules on EL-4 and C1498 cells, respectively. This is consistent with studies on human leukemic cells in which a decreased expression of class I molecules was observed in cells of five out of six acute lymphoblastic leukemia patients by Van der Harst et al. (42) and in at least $28 \%$ of acute myeloblastic leukemia blasts by Pozzi et al. (43). Collectively, these data suggest that decreased class I expression is common in leukemic cells. Such a decrease in density of class I molecules is sufficient to abrogate the immunogenicity of tumor cells and could allow such cells to escape immune surveillance (34-36). However, our experiments did not focus on the immunogenicity of leukemic cells, as our effectors were always primed against normal C57BL/6J cells, but on their sensitivity to CTL-mediated cytotoxicity. Does the lowered density of class I molecules cause a general and unselective decrease in MiHA expression that could explain the complete resistance of leukemic cells to CTLs targeted to H-1, H-7, H-9, and H-25 MiHAs? Two facts argue against this hypothesis. First, leukemic cells retained sensitivity to CTLs directed against other MiHAs (Figs. 1 and 2). Second, Koeppen et al. observed that tumors with deficient expression of class I molecules usually lacked immunogenicity but retained sensitivity to CTL-mediated killing unless the deficiency was practically total (44). It was therefore important to evaluate MiHA expression by leukemic cells. The sequence of these MiHAs is unknown and no anti-MiHA antibody is available. Thus, the only feasible approach was to see whether peptides extracted from these cells could sensitize normal target cells to lysis by anti-MiHA CTLs. This approach allowed us to provide what we believe to be the first molecular evidence that leukemic cells express some but not all MiHAs and that this expression may determine sensitivity to CTLs in vitro and in vivo. Although we could not compare the sequences of the major MiHA peptide obtained from normal and leukemic cells (Fig. 5, a$c$ ), elution precisely in the same HPLC fraction suggests that they were identical.

CTL effectors able to kill leukemic cells could be generated only by immunization with cells differing at multiple MiHA loci and not with cells presenting a single MiHA difference. Why is this so? It has been estimated that the number of MiHA gene differences between two MHC-identical inbred strains of mice is at least 40 and may be much greater (hundreds or thousands?) $(45,46)$. Unexpectedly, a number of studies using different approaches have shown that CTLs generated in this immunogenetic setting usually recognized only two MiHAs (28, $32,41,47)$. These were called immunodominant, whereas other MiHAs were said to be dominated or recessive. The molecular basis for this phenomenon remains unclear, although there is evidence that $(i)$ it results from competition of MiHAs for processing or association with MHC molecules at the antigenpresenting cell level, and ( $i i)$ it may be influenced by the ability of some MiHAs to trigger both $\mathrm{CD}^{+}$and $\mathrm{CD}{ }^{+} \mathrm{T}$ cell responses $(28,32,48)$. Accordingly, in the C3H.SW anti-C57BL/ $6 \mathrm{~J}$ combination, we detected MiHAs in only two HPLC fractions, as did Yin et al. using BALB.B anti-C57BL/6J effectors (28). In four out of four strain combinations in which we primed CTLs against immunodominant MiHAs, effectors killed leukemic blasts (Fig. 1). As a rule (one possible exception has been reported [28]), CTLs generated in C57BL/6J congenic strains (differing from $\mathrm{C} 57 \mathrm{BL} / 6 \mathrm{~J}$ by a single MiHA gene) recognize immunorecessive MiHAs $(32,47)$. CTLs generated in four out of four strain combinations of this type killed normal but not leukemic blasts (Fig. 2). These results provide strong evidence that only immunodominant MiHAs are well expressed at the surface of leukemic cells. H-3 and H-4 "haplotypes" probably represent an intermediate between these two extremes (first-order dominant MiHAs and totally recessive MiHAs), as there is a hierarchy in immunodominance (47).

Additional studies will be required to understand the molecular bases for disturbed MiHA expression. Basal expression of MiHA peptides is governed mainly by three types of genes: genes encoding classic MHC molecules, those involved in anti- 
gen processing, and those encoding the MiHAs themselves. Down-regulated expression of the first two types of genes by neoplastic cells has been described and would be compatible with the low surface density of class I molecules we observed on EL-4 and C1498 leukemic blasts $(34,49)$. As immunorecessive MiHAs are less effective than dominant MiHAs at some point in the presentation pathway, they could possibly be affected selectively by a deficit involving antigen processing or class I expression. It is more difficult to explain our results by postulating a deficient expression of MiHA gene products, i.e., precursor proteins whose processing yields MiHA peptides. How could this anomaly affect all recessive MiHAs and spare those that are immunodominant? To give a plausible explanation, we would have to hypothesize that recessive MiHAs are differentiation antigens expressed only on mature cells, whereas dominant MiHAs are expressed on both mature and immature cells. Meanwhile, our observation that on leukemic cells only dominant MiHA are well expressed and are efficiently recognized by CTLs in vivo and in vitro suggests that they should be prime candidates as targets for leukemia immunotherapy.

\section{Acknowledgments}

This work has been supported by the National Cancer Institute of Canada and the Cancer Research Society.

\section{References}

1. Rammensee, H. G., K. Falk, and O. Rötzschke. 1993. Peptides naturally presented by MHC class I molecules. Annu. Rev. Immunol. 11:213-244.

2. Germain, R. N. 1994. MHC-dependent antigen processing and peptide presentation: providing ligands for T lymphocyte activation. Cell. 76:287-299.

3. Perreault, C., F. Decary, S. Brochu, M. Gyger, R. Bélanger, and D. C. Roy. 1990. Minor histocompatibility antigens. Blood. 76:1269-1280.

4. Loveland, B., C. R. Wang, H. Yonekawa, E. Hermel, and K. FischerLindahl. 1990. Maternally transmitted histocompatibility antigen of mice: a hydrophobic peptide of a mitochondrially encoded protein. Cell. 60:971-980.

5. Wallny, H. J., and H. G. Rammensee. 1990. Identification of classical minor histocompatibility antigen as cell-derived peptide. Nature (Lond.). 343:275-278.

6. Vacchio, M. S., and R. J. Hodes. 1989. Selective decreases in T cell receptor $\mathrm{V} \beta$ expression. Decreased expression of specific $\mathrm{V} \beta$ families is associated with expression of multiple MHC and non-MHC gene products. J. Exp. Med. 170:1335-1346.

7. Hogquist, K. A., M. A. Gavin, and M. J. Bevan. 1993. Positive selection of $\mathrm{CD8}^{+} \mathrm{T}$ cells induced by major histocompatibility complex binding peptides in fetal thymic organ culture. J. Exp. Med. 177:1469-1473.

8. Ashton-Rickardt, P. G., A. Bandeira, J. R. Delaney, L. Van Kaer, H. P. Pircher, R. M. Zinkernagel, and S. Tonegawa. 1994. Evidence for a differential avidity model of $\mathrm{T}$ cell selection in the thymus. Cell. 76:651-663.

9. Rammensee, H. G., H. Schild, and U. Theopold. 1989. Protein-specific cytotoxic $\mathrm{T}$ lymphocytes. Recognition of transfectants expressing intracellular, membrane-associated or secreted forms of $\beta$-galactosidase. Immunogenetics. 30:296-302.

10. Boon, T. 1992. Toward a genetic analysis of tumor rejection antigens. Adv. Cancer Res. 58:177-210.

11. Perreault, C., S. Brochu, P. Fontaine, N. Tremblay, and S. Pion. 1994. The role of MHC-associated self peptides in transplantation and immunosurveillance. Clin. Immunol. Immunopathol. 2:130-135.

12. Van der Bruggen, P., and B. Van den Eynde. 1992. Molecular definition of tumor antigens recognized by T lymphocytes. Curr. Opin. Immunol. 4:608612.

13. De Bueger, M., A. Bakker, J. J. Van Rood, F. Van der Woude, and E. Goulmy. 1992. Tissue distribution of human minor histocompatibility antigens: ubiquitous versus restricted tissue distribution indicates heterogeneity among human cytotoxic T lymphocyte-defined non-MHC antigens. J. Immunol. 149:17881794.

14. Miconnet, I., V. De La Selle, C. Tucek, R. Huchet, D. Bonardelle, and M. Bruley-Rosset. 1994. Tissue distribution and polymorphism of minor histocompatibility antigens involved in GVHR. Immunogenetics. 39:178-186.

15. Truitt, R. L., A. V. LeFever, C. C. Y. Shih, J. M. Jeske, and T. M. Martin.
1990. Graft-vs-leukemia effect. In Graft-vs-Host Disease. S. J. Burakoff, H. J. Deeg, J. Ferrara, and K. Atkinson, editors. Marcel Dekker Inc., New York. $177-$ 204.

16. Horowitz, M. M., R. P. Gale, P. M. Sondel, J. M. Goldman, J. Kersey, H. J. Kolb, A. A. Rimm, O. Ringden, C. Rozman, B. Speck, R. L. Truitt, F. E Zwaan, and M. M. Bortin. 1990. Graft-versus-leukemia reactions after bone marrow transplantation. Blood. 75:555-562.

17. Antin, J. H. 1993. Graft-versus-leukemia: no longer an epiphenomenon. Blood. 82:2273-2277.

18. Ritz, J. 1994. Tumor immunity: will new keys unlock the door? J. Clin. Oncol. 12:237-238.

19. Bortin, M. M., R. L. Truitt, A. A. Rimm, and F. H. Bach. 1979. Graftversus-leukemia activity induced by alloimmunization without augmentation of graft-versus-host activity. Nature (Lond.). 281:490-491.

20. Truitt, R. L., C. Y. Shih, A. V. Lefever, L. D. Tempelis, M. Andreani, and M. M. Bortin. 1983. Characterization of alloimmunization-induced T lymphocytes reactive against AKR leukemia in vitro and correlation with graft-versus-leukemia activity in vivo. J. Immunol. 131:2050-2058.

21. Truitt, R. L., C. C. Y. Shih, and A. V. Lefever. 1986. Manipulation of graft-versus-host disease for a graft-versus-leukemia effect after allogeneic bone marrow transplantation in AKR mice with spontaneous leukemia/lymphoma. Transplantation. 41:301-310.

22. Butturini, A., and R. P. Gale. 1988. T cell depletion in bone marrow transplantation for leukemia: current results and future directions. Bone Marrow Transplant. 3:185-192.

23. Charak, B. S., R. K. Brynes, S. Katsuda, S. Groshen, S. C. Chen, and A. Mazumder. 1991. Induction of graft versus leukemia effect in bone marrow transplantation: dosage and time schedule dependency of interleukin 2 therapy. Cancer Res. 51:2015-2020.

24. Storkus, W. J., H. J. Zeh, M. J. Maeurer, R. D. Salter, and M. T. Lotze. 1993. Identification of human melanoma peptides recognized by class I restricted tumor infiltrating T lymphocytes. J. Immunol. 151:3719-3727.

25. Ljunggren, H. G., N. J. Stam, C. Ohlen, J. J. Neefjes, P. Höglund, M. T. Heemels, J. Bastin, T. N. M. Schumacher, A. Townsend, K. Kärre, and H. L. Ploegh. 1990. Empty MHC class I molecules come out in the cold. Nature (Lond.). 346:476-480.

26. Roderick, T. H., and J. H. Guidi. 1989. Strain distribution of polymorphic variants. In Genetic Variants and Strains of the Laboratory Mouse, 2nd edition. M. F. Lyon and A. G. Searle, editors, Oxford University Press, New York. $663-$ 664.

27. Moobraten, L. E. 1991. Histocompatibility and other cellular antigens. In Handbook on Genetically Standardized JAX Mice. M. C. Green and B. A. Witham, editors, 4th edition, The Jackson Laboratory, Bar Harbor, ME. p. 45.

28. Yin, L., G. Poirier, O. Neth, J. J. Hswan, N. F. Totty, and H. J. Stauss. 1993. Few peptides dominate cytotoxic $\mathrm{T}$ lymphocyte responses to single and multiple minor histocompatibility antigens. Int. Immunol. 5:1003-1009.

29. Roopenian, D. C., and A. P. Davis. 1989. Responses against antigens encoded by the H-3 histocompatibility locus: antigens stimulating class I MHCand class II MHC-restricted T cells are encoded by separate genes. Immunogenetics. 30:335-343.

30. Davis, A. P., and D. C. Roopenian. 1990. Complexity at the mouse minor histocompatibility locus H-4. Immunogenetics. 31:7-12.

31. Kane, K. P., and M. F. Mescher. 1993. Activation of CD8-dependent cytotoxic $\mathrm{T}$ lymphocyte adhesion and degranulation by peptide class I antigen complex. J. Immunol. 150:4788-4797.

32. Wettstein, P. J. 1986. Immunodominance in the T-cell response to multiple non-H-2 histocompatibility antigens. III. Single histocompatibility antigens dominate the male antigen. J. Immunol. 137:2073-2079.

33. Lai, P. K. 1985. Antigen competition in cytotoxic T cell response to minor histocompatibility antigens. Transplantation. 39:638-643.

34. Browning, M. J., P. Krausa, A. Rowan, D. C. Bicknell, J. G. Bodmer, and B. W. Bodner. 1993. Tissue typing the HLA-A locus from genomic DNA by sequence-specific PCR: comparison of HLA genotype and surface expression on colorectal tumor cell lines. Proc. Natl. Acad. Sci. USA. 90:2842-2845.

35. Garrido, F., T. Cabrera, A. Concha, S. Glew, F. Ruiz-Cabello, and P. L. Stern. 1993. Natural history of HLA expression during tumor development. Immunol. Today. 14:491-499.

36. Tsioulias, G. J., G. Triadafilopoulos, E. Goldin, E. D. Papavassilou, S. Rizos, P. Bassioukas, and B. Rigas. 1993. Expression of HLA class I antigens in sporadic adenomas and histologically normal mucosa of the colon. Cancer Res. 53:2374-2378.

37. Griem, P., H. J. Wallny, K. Falk, O. Rötzschke, B. Arnold, G. Schönrich, G. Hammerling, and H. G. Rammensee. 1991. Uneven tissue distribution of minor histocompatibility proteins versus peptides is caused by MHC expression. Cell. 65:633-640.

38. Falkenburg, J. H. F., H. M. Goselink, D. Van der Harst, A. P. Van Luxemburg-Heijs, Y. M. C. Kooy-Winkelaar, L. M. Faber, J. De Kroon, A. Brand, W. E. Fibbe, R. Willemze, and E. Goulmy. 1991. Growth inhibition of clonogenic 
leukemic precursor cells by minor histocompatibility antigen-specific cytotoxic $\mathrm{T}$ lymphocytes. J. Exp. Med. 174:27-33.

39. Faber, L. M., A. P. van Luxemburg-Heijs, R. Willemze, and J. H. F. Falkenburg. 1992. Generation of leukemia-reactive cytotoxic T lymphocyte clones from the HLA-identical bone marrow-donor of a patient with leukemia. J. Exp. Med. 176:1283-1289.

40. Ando, K., L. G. Guidotti, S. Wirth, T. Ishikawa, G. Missale, T. Moriyama, R. D. Schreiber, H. J. Schlicht, S. N. Huang, and F. V. Chisari. 1994. Class Irestricted cytotoxic $\mathrm{T}$ lymphocytes are directly cytopathic for their target cells in vivo. J. Immunol. 152:3245-3253.

41. Tremblay, N., P. Fontaine, and C. Perreault. 1994. T lymphocyte responses to multiple minor histocompatibility antigens generate both self-major histocompatibility complex-restricted and cross-reactive cytotoxic $\mathrm{T}$ lymphocytes. Transplantation. 58:59-67.

42. Van der Harst, D., E. Goulmy, J. H. F. Falkenburg, Y. M. C. KooyWinkelaar, S. A. P. Van Luxemburg-Heijs, H. M. Goselink, and A. Brand. 1994. Recognition of minor histocompatibility antigens on lymphocytic and myeloid leukemic cells by cytotoxic T-cell clones. Blood. 83:1060-1066.

43. Pozzi, C., D. Peruccio, A. M. Dall'Omo, S. D'Alfonso, P. Savoia, M. G.
Guerra, R. Miniero, M. Lecchi, L. Resegotti, and P. Richiardi. 1990. Altered expression of HLA-A,B specificities on acute lymphoid and myeloid leukaemia blasts. J. Immunogenet. 17:161-168.

44. Koeppen, H., M. Acena, A. Drolet, D. A. Rowley, and H. Schreiber. 1993. Tumors with reduced expression of a cytotoxic $T$ lymphocyte recognized antigen lack immunogenicity but retain sensitivity to lysis by cytotoxic $\mathrm{T}$ lymphocytes. Eur. J. Immunol. 23:2770-2776.

45. Loveland, B., and E. Simpson. 1986. The non-MHC transplantation antigens: neither weak nor minor. Immunol. Today. 7:223-229.

46. Fisher-Lindhal, K. 1991. Minor histocompatibility antigens. Trends Genet. 7:219-224.

47. Wettstein, P. J., and D. W. Bailey. 1982. Immunodominance in the immune response to multiple histocompatibility antigens. Immunogenetics. 16:47-58.

48. Roopenian, D. C. 1992 . What are minor histocompatibility loci? A new look at an old question. Immunol. Today. 13:7-10.

49. Restifo, N. P., F. Esquivel, Y. Kawakami, J. W. Yewdell, J. J. Mulé, S. A. Rosenberg, and J. R. Bennink. 1993. Identification of human cancers deficient in antigen processing. J. Exp. Med. 177:265-272. 